Virtual Mentor. January 2003, Volume 5, Number 1.

doi: 10.1001/virtualmentor.2003.5.1.fred1-0301

From the Editor

\title{
Form Follows Function: Virtual Mentor's New Format
}

\section{The journal editor explains changes to the journal and how the new format will better serve a professional audience. This format will include tools to be used by educators, such as PowerPoint presentations, case studies, and article reviews. .}

Chicago is home to many of the world's most recognizable buildings, as well as some of its most renowned architects. One of these architects was Louis Sullivan. His designs were based on the principle that the functional use of a building should dictate the shape and layout of its physical spaces. In other words, Sullivan espoused the importance of form following function.

Chicago is also home to one of the world's leading professional institutions, the American Medical Association (AMA). The AMA was founded more than 150 years ago, in large part to establish a code of ethics for medicine - the first such national codification of professional ethics in history [1]. Since its inception more than 3 years ago, Virtual Mentor (VM) has been guided by these historical roots in establishing an online forum for exploring and addressing ethical issues in medicine. While VM's mission has not changed, this month's issue reflects significant changes in editorial content. It is our expectation that Virtual Mentor's new form will better serve its longstanding function strengthening the ethics and professionalism of tomorrow's physicians.

Our readers will notice Virtual Mentor's shift to a more thematic focus. Every month, a topic of ethical relevance to the practice of good medicine will be explored and addressed. By examining a single topic from many perspectives, we hope our audience will not only gain a greater understanding of the ethical issues in medicine, and thus, how better to address these challenges, but also of the complex relationship between the ethical dimension of care and the clinical and legal considerations.

In addition to a more thematic focus, a core portion of $V M$ content will be presented in a form that can be printed and readily used by medical educators in formal teaching settings. In each VM issue, the core set of teaching tools may include:

- PowerPoint ${ }^{\circledR}$ presentations with explicit learning objectives that can be used in medical school courses or hospital grand rounds;

- Cases in clinical ethics and/or health law with expert commentary;

- Journal article reviews with questions for discussion in easily printed formats for distribution to students and residents;

- Glossary of relevant terms and concepts;

- Evaluation instruments that test students' knowledge and understanding of issues and topics covered by a theme issue.

It seems fitting to me that the initial issue of the new and improved Virtual Mentor is on the guiding ethic that has served as the foundation for sound medical practice - first do no harm. With the increasing advances in medical technology, physicians have the potential to do great good for patients, but also to inflict great harm. In this issue, we explore and address the challenges that physicians confront when they decide that further treatment would be harmful to their patients. As always, I encourage and welcome your suggestions and thoughts about how we can improve 
Virtual Mentor's content and form to better fulfill our function and mission.

All the best,

Audiey Kao, MD, PhD

\section{Reference}

1. Baker R, Caplan AL, Emanuel LL, Latham SR. The American Medical Ethics Revolution: How the AMA's Code of Ethics Has Transformed Physician's Relationship to Patients, Professionals, and Society. Baltimore, Md: Johns Hopkins University Press; 1999.

Google Scholar

The viewpoints expressed on this site are those of the authors and do not necessarily reflect the views and policies of the AMA.

(C) 2003 American Medical Association. All Rights Reserved. 